\title{
Monitoring of Gangotri glacier using remote sensing and ground observations
}

\author{
H S Negi*, N K Thakur, A Ganju and Snehmani \\ Snow 8 Avalanche Study Establishment, Him Parisar, Sector-37A, Chandigarh 160 036, India. \\ *Corresponding author.e-mail: hs.negi@sase.drdo.in
}

In this study, Gangotri glacier was monitored using Indian Remote Sensing (IRS) LISS-III sensor data in combination with field collected snow-meteorological data for a period of seven years (2001-2008). An overall decreasing trend in the areal extent of seasonal snow cover area (SCA) was observed. An upward shifting trend of wet snow line was observed in the beginning of melt period, i.e., in May and dominant wet snow conditions were observed between May and October. Snow meteorological parameters collected in the Gangotri sub-basin suggest reduction in fresh snowfall amount during winter, increase in rainfall amount during summer, decrease in snowfall days, increase in rainfall days and rising trend of average temperature. The prevailing wet snow condition on glacier has caused scouring of slopes which led the excessive soil/debris deposition on the glacier surface. This was observed as one of the major factor for activating fast melting and affecting the glacier health significantly. Apart from climatic conditions, terrain factors were observed for changing the glacio-morphology. The significant changes on the glacier surface were observed in the regions of abrupt slope change. The above factors affecting the Gangotri glacier health were also validated using high resolution satellite imageries and field visit. A deglaciation of $6 \%$ in overall area of Gangotri glacier was observed between the years 1962 and 2006.

\section{Introduction}

Glaciers are one of the important natural resources in Himalaya and have a great importance for perennial source of water, hydropower generation and regional climatology. The morphological characteristic of a glacier categorizes it into ice sheet, ice cap and glacier constrained by topography. The ice sheet and ice cap are formed when underneath topography is fully covered with ice and do not affect the flow of glacier (Singh et al. 2011). Valley glaciers and cirque glaciers are examples of constrained by topography and terrain geometry (Paterson 1994). Majority of glaciers in Himalaya are valley type and constrained by topography (Bahuguna 2003). These glaciers are the main sources of many river systems originating in Himalaya. Therefore, melt water from these glaciers becomes important during summer months.

Nowadays, there is lot of concern about the disappearance of glaciers due to global warming and climate change. Since glaciers are sensitive to climate, they are considered to be an indicator of climate change. Therefore, monitoring of snow cover pattern and assessment of the possible changes in glacier health are required. Remote sensing techniques provide multi-sensor and multi-temporal data for monitoring the glacier properties such as glacier area, length, surface elevation, albedo, equilibrium line altitude (ELA), terminus position, volume, accumulation/ablation rates, accumulation area ratio (AAR) from which glacier mass balance can be inferred. Such tool is particularly useful for inaccessible areas in conjunction with field-based

Keywords. Snow; glacier; Himalaya; Gangotri; LISS-III; snow cover area. 
glaciological measurements (Kulkarni 1992a; Krishna 1996; Konig et al. 2001; Kulkarni and Bahuguna 2002; Bahuguna et al. 2007; Kulkarni et al. 2007).

Several studies were conducted on Himalayan glaciers to estimate recession rates using snout monitoring, remote sensing and geomorphological evidences. Most of these studies related to glacier retreat in Himalaya are attributed to climatic variations or global warming (Bhutiyani 1999; Kulkarni et al. 2002a, 2005; Kulkarni 2007; Bhutiyani et al. 2008; Hasnain 2008). Recession also leads to volume loss in glaciers (Dobhal et al. 2004). Kulkarni et al. (2011) estimated the glacial retreat for 1868 glaciers in 11 basins of Indian Himalaya since 1962 and shown an overall deglaciation of $16 \%$. They attributed global warming in the Himalayan cryosphere has an influence on the glacial retreat, negative mass balance and early melting of seasonal snow cover. In addition, they reported that the number of glaciers with lower areal extent has increased due to fragmentation in higher areal extent glaciers. At present, apart from global warming, black carbon or anthropogenic activities have also been reported as one of the major factors for depleting the Himalayan glaciers (Hansen and Nazarenko 2004; IPCC 2007; Yasunari et al. 2010). In addition, there may be other non-climatic factors such as ice dynamics, glacier hypsometry (the distribution of glacier area versus elevation), topography (Racoviteanu et al. 2008; Dobhal et al. 2004) and wet snow avalanches which can affect the glacier health.

Gangotri is one of the largest glaciers that lies in the central Himalaya. This is a valley type glacier (Naithani et al. 2001) in Bhagirathi basin and the source of a major river system Ganga in northern India. Numerous studies have been reported on the recession of terminus/snout position and varying rates of retreat were reported for different timespans of the last century (Bahuguna et al. 2007; Kumar et al. 2008; Nainwal et al. 2008). Naithani et al. (2001) reported geomorphological evidences of retreat of the Gangotri glacier and its characteristics. Philip and Ravindran (1998) identified the major features/landforms of Gangotri glacier from Landsat TM data using bands 4,5 and 7. Venkataraman et al. (2005) made the use of SAR Interferometry technique for the generation of DEM and glacier movement of Gangotri glacier using ERS-1 and 2 tandem data. Mohite et al. (2007) carried out the analysis of snow cover maps for different months of 2003 and 2004 using LISS-III and AWiFS data. They observed that the snowfall in 2002-2003 season was higher than in 2003-2004 and the melting of snow started in early March of 2004 and thus resulting in depletion of snow cover extent. Bahuguna et al. (2007) identified the position of the snout using the merged product of PAN and LISS III sensor's data of IRS 1C and demonstrated the use of satellite stereo data to determine the thickness of the glacier ice across the section of the retreat. As most of the above studies are either restricted to snout region or only field based and the studies carried out using remote sensing were either with limited satellite imageries or not supported with field data. However, it is equally important to know the different changes taking place on the higher regions of glacier surface and the other affecting factors. Therefore, in the present study, monitoring of snow cover area (SCA) and wet snow line were carried out for Gangotri glacier using multi-spectral remote sensing satellite data for a period of seven years. The wet snow monitoring has the importance in estimating the start of ablation period and its variation with altitude which can be useful for hydrological modelling as it contributes to the melt runoff at a particular point of time. Attempts were made to see the effect of wet snow on Gangotri glacier. The snow-meteorological data were analysed to support the changes observed by satellite data. The terrain analysis was carried out to understand the surface changes on the glacier bed and further validations were carried out using high resolution satellite data and field visits.

\section{Study area and data used}

The study area of Gangotri glacier is bounded between longitude $78^{\circ} 59^{\prime} 30^{\prime \prime}$ and $79^{\circ} 17^{\prime} 45^{\prime \prime} \mathrm{E}$, and latitude $30^{\circ} 43^{\prime} 00^{\prime \prime}$ and $30^{\circ} 57^{\prime} 15^{\prime \prime} \mathrm{N}$ and covers in part of 04 Survey of India (SoI) map sheets of 1:50,000 scale. The total area of Gangotri subbasin selected as the study area is approximately $417 \mathrm{~km}^{2}$ out of which $54 \%$ of the area are glaciated. This glacier is flowing towards north-west direction. The altitude of the glacier varies from 4000 to $7000 \mathrm{~m}$ and has a length of approximately $30 \mathrm{~km}$.

In the present study, LISS-III sensor data of IRS-1C/1D satellites was used for the monitoring of snow cover. This sensor has four spectral bands in green $(0.52-0.59 \mu \mathrm{m})$, red $(0.62-$ $0.68 \mu \mathrm{m})$, NIR $(0.77-0.86 \mu \mathrm{m})$ and SWIR $(1.55-$ $1.70 \mu \mathrm{m})$ wavelength regions. LISS-III has $23.5 \mathrm{~m}$ spatial resolution in first three bands (VNIR) and $70.5 \mathrm{~m}$ spatial resolution in SWIR band with a swath of $141 \mathrm{~km}$. The temporal resolution of satellites is 24-25 days, but the frequency of data availability from both IRS-1C/1D satellites is more. The selection of LISS-III sensor is due to the only available multispectral IRS sensor in the study period with reasonable spatial resolution. In this investigation, total 33 multitemporal cloud-free satellite imageries were analyzed for the period between October 2001 and 
May 2008 (table 1). The pre-winter (September/ October) PAN imagery of IRS satellite with spatial resolution of $5.8 \mathrm{~m}$ was used for the mapping of latest glacier extent, because during this period snow cover is minimal and glacier is fully exposed. In addition, false colour composite (FCC) of visible and near-infrared images were also used to map glacier boundary, due to significant difference in reflectance from glacial and non-glacial features (Kulkarni 1992b). In addition, high resolution Cartosat-1 image (spatial resolution $2.5 \mathrm{~m}$ ) of 28 September 2006 was also used for monitoring recent changes in glacio-morphological features. The satellite data used for the glacier boundary are shown in table 2. The glacial extent available on SoI topographic maps, surveyed in 1962 was also delineated in GIS environment for the glacier boundary. A DEM of the study area was generated at $6 \mathrm{~m}$ pixel resolution using contours and spot heights of

Table 1. Total numbers of LISS-III scenes used for the snow cover monitoring of Gangotri glacier.

\begin{tabular}{|c|c|c|}
\hline Sl. no. & Date of pass & Satellite \\
\hline 1 & 10 October 2001 & IRS-1D \\
\hline 2 & 23 May 2002 & IRS-1D \\
\hline 3 & 14 June 2002 & IRS-1C \\
\hline 4 & 8 July 2002 & IRS-1C \\
\hline 5 & 1 August 2002 & IRS-1C \\
\hline 6 & 22 February 2003 & IRS-1D \\
\hline 7 & 8 February 2003 & IRS-1D \\
\hline 8 & 2 June 2003 & IRS-1D \\
\hline 9 & 19 December 2003 & IRS-1D \\
\hline 10 & 7 February 2004 & IRS-1D \\
\hline 11 & 3 March 2004 & IRS-1D \\
\hline 12 & 15 May 2004 & IRS-1D \\
\hline 13 & 11 June 2004 & IRS-1D \\
\hline 14 & 19 September 2004 & IRS-1D \\
\hline 15 & 1 October 2004 & IRS-1C \\
\hline 16 & 8 November 2004 & IRS-1D \\
\hline 17 & 3 December 2004 & IRS-1C \\
\hline 18 & 12 December 2004 & IRS-1C \\
\hline 19 & 16 February 2005 & IRS-1D \\
\hline 20 & 27 May 2005 & IRS-1D \\
\hline 21 & 22 June 2005 & IRS-1C \\
\hline 22 & 9 August 2005 & IRS-1C \\
\hline 23 & 4 September 2005 & IRS-1D \\
\hline 24 & 12 May 2006 & IRS-1D \\
\hline 25 & 1 July 2006 & IRS-1D \\
\hline 26 & 14 September 2006 & IRS-1D \\
\hline 27 & 3 November 2006 & IRS-1D \\
\hline 28 & 23 December 2006 & IRS-1D \\
\hline 29 & 8 March 2007 & IRS-1D \\
\hline 30 & 19 May 2007 & IRS-1C \\
\hline 31 & 17 March 2008 & IRS-1D \\
\hline 32 & 6 May 2008 & IRS-1D \\
\hline 33 & 31 May 2008 & IRS-1D \\
\hline
\end{tabular}

Table 2. Multi-sensor satellite data used for the delineation of glacier boundary.

\begin{tabular}{lll}
\hline Sl. no. & \multicolumn{1}{c}{ Date of pass } & Satellite and sensor \\
\hline 1 & 26 October 2001 & IRS-1C, PAN \\
2 & 8 July 2002 & IRS-1C, LISS-III \\
3 & 19 September 2004 & IRS-1D, LISS-III \\
4 & 9 August 2005 & IRS-1C, LISS-III \\
5 & 28 September 2006 & IRS-P5, Cartosat-1 \\
\hline
\end{tabular}

1:50,000 scale map sheets and used for geographical analysis.

The field snow-meteorological data, (e.g., snowfall, rainfall, temperatures, etc.), recorded at Snow and Avalanche Study Establishment (SASE) manned observatory located at Bhojbasa (3800 m) in Gangotri sub-basin, were used in the study. Field photographs were analyzed for the validation of changes observed in glacio-morphological features.

\section{Methodology}

The generation of digital database and preprocessing of LISS-III satellite data were carried out in ERDAS imagine (ver. 9.1) software and satellite data were geo-referenced up to subpixel accuracy using ground control points such as bends, junctions of streams/nallahs, etc. Initially coordinates of ground control points (GCP) were measured using SoI maps of 1:50,000 scale and later on image-to-image registration was carried out for the time series analysis. The digital numbers (DN) were converted into spectral radiances using the following equation (Markham and Barker 1986):

$$
L_{\lambda}=\operatorname{Gain}_{\lambda} \times D N_{\lambda}+\operatorname{Bias}_{\lambda}
$$

where $\operatorname{Gain}_{\lambda}$ is the calibration gain coefficient of the sensor $\left(\mathrm{mW} \mathrm{cm}{ }^{-2} \mathrm{sr}^{-1} \mu \mathrm{m}^{-1}\right.$ counts $\left.^{-1}\right), D N_{\lambda}$ is the digital number of a pixel in a particular band (counts) and Bias ${ }_{\lambda}$ is the calibration offset of the sensor band $\left(\mathrm{mW} \mathrm{cm} \mathrm{cm}^{-2} \mathrm{sr}^{-1} \mu \mathrm{m}^{-1}\right)$. The dark object subtraction (DOS) model was used to correct the atmospheric effect from the image. This correction can be performed in multispectral data by observing the radiance recorded over target areas of essentially zero values such as deep clear water in the NIR region of the spectrum (Chavez 1988; Song et al. 2001). Therefore, any signal observed over such an area represents the path radiance and these values can be subtracted from all the pixels in all the bands. In the present study, the radiance value was collected of water body present in the full scene of LISS-III and this radiance value (Radiance $_{d}$ ) was subtracted as given 
by following equation to correct every band for atmospheric correction:

$$
L_{i \lambda}=\text { Radiance }_{i \lambda}-\left(K_{i \lambda} \times \text { Radiance }_{d}\right),
$$

where $L_{i \lambda}$ is the atmospherically corrected radiance of the pixel, $K_{i \lambda}$ is the atmospheric coefficient constant (multiplication factor) for each band (Chavez 1988) and Radiance ${ }_{d}$ is radiance of the dark object (water body) in NIR band. By considering the snow cover as a lambertian surface, the reflectance of each LISS-III band was derived from the radiance values (Dozier 1989a; Kulkarni et al. 2002b; Srinivasulu and Kulkarni 2004):

$$
R_{i \lambda}=\frac{\pi L_{i \lambda} d^{2}}{E_{\operatorname{sun}_{\lambda}} \operatorname{Cos}(z)},
$$

where $R_{i \lambda}$ is the reflectance of a pixel in a particular band, $L_{\lambda}$ is the atmospheric corrected spectral radiance from pixel in each band $\left(\mathrm{mW} / \mathrm{cm}^{2} / \mathrm{sr} / \mu \mathrm{m}\right), d$ is earth-sun distance in astronomical units (AU), $E_{\mathrm{sun}_{\lambda}}$ is the mean solar exoatmospheric spectral irradiance $\left(\mathrm{mW} / \mathrm{cm}^{2} / \mu \mathrm{m}\right)$ and $z$ is the solar zenith angle (degree). The values of the mean solar exoatmospheric spectral irradiance $\left(E_{\operatorname{sun}_{\lambda}}\right)$ for IRS-1C, LISS-III bands are 185.111, 158.376, 110.251, $24.042 \mathrm{mWcm}^{-2} \mu \mathrm{m}^{-1}$ and IRS-1D, LISS-III bands are 185.216, 157.731, 109.666, 24.062, respectively (Srinivasulu 2003).

The normalized difference snow index (NDSI) uses the high and low reflectance of snow in visible (green) and shortwave infrared (SWIR) regions respectively for the estimation of snow cover area (Dozier 1989b; Hall et al. 1995):

$$
\begin{aligned}
& \text { NDSI } \\
& =\frac{\text { Reflectance }(\text { green })-\text { Reflectance (SWIR) }}{\text { Reflectance (green) }+ \text { Reflectance (SWIR) }} .
\end{aligned}
$$

NDSI has the advantage that it can discriminate between snow and cloud (except high cirrus cloud), as cloud reflectance is high in SWIR region. In addition, NDSI has the advantage that it can take care of snow under mountain shadows (Kulkarni et al. 2004) and it also tends to reduce the influence of atmospheric effects and topographic effects/viewing geometry (Salomonson and Appel 2004; Negi et al. 2009). The snow versus nonsnow area was classified using the NDSI threshold value of 0.4 , which is the value generally reported for multispectral data (Dozier 1989b) and from field spectro-radiometer measurements for different types of snow by Negi et al. $(2009,2010)$ and Negi and Kokhanovsky (2011).

This is well established by theoretically and experimentally that as the liquid water content increases in unsaturated snow, an effective grain size increases caused by the grains to cluster (Colbeck 1982), and the snow reflectance decreases in the near-infrared (NIR) wavelengths (O'Brien and Munis 1975; Wiscombe and Warren 1980). In addition to changing the effective grain size by its mere presence; liquid water also speeds up the rate of grain growth. Therefore a short exposure to melting conditions can reduce the reflectance considerably. Thus snow can be classified as dry or wet snow using NIR band reflectance data. Here we consider that the wet (melting) snow is not refreezing by and large, because it would again melt in the following days once the temperature increases. New dry snow has a very high reflectance in visible region $(>90 \%)$ and for this the visible channels green, red and NIR bands of LISS-III sensor saturates due to its less radiometric resolution. Gupta et al. (2005) used the LISS-III data for snow classification and observed that the NIR band saturate at reflectance of approximately more than $50 \%$ and they classified snow cover area into dry and wet snow classes using NIR reflectance $>50 \%$ (dry snow) and $<50 \%$ (wet snow). Same methodology has been adopted in the present study for the snow classification. The trends of snow covered area, dry and wet snow classes were analyzed using multi-temporal data of Gangotri glacier.

In Himalaya snowfall takes place due to western disturbances generally during winter and winter period is defined between November and April, and rest of the months is defined as summer period (Bhutiyani et al. 2007). The snow cover analysis was carried out using satellite retrieved and ground observed data on seasonal basis. Daily snow-melt data such as temperatures (maximum and minimum), fresh snowfall and rainfall recorded from field observatory were analyzed for comparison/validation of snow cover area and snow characteristics. The topographic analysis was carried out using digital elevation model (DEM) of the study area using SoI mapsheets at 1:50,000 scale. Terrain parameters such as slope, aspect, and elevation were generated using DEM. Based on slope change within glacier bed, i.e., glacier constrained by topography regions were identified and mapped. Changes were also analyzed in these regions based on the variations in tone and textures of two LISSIII images of dated 10 October 2001 and 9 October 2006 imageries. The satellite data were selected such that the solar geometry (incidence and azimuth angles) remain approximately same due to nearly anniversary dates. The images were classified using unsupervised classification (ISODATA technique). These classified images were used to produce a thematic image of separate class for every coincidence of classes in the classified images using matrix analysis. The output 


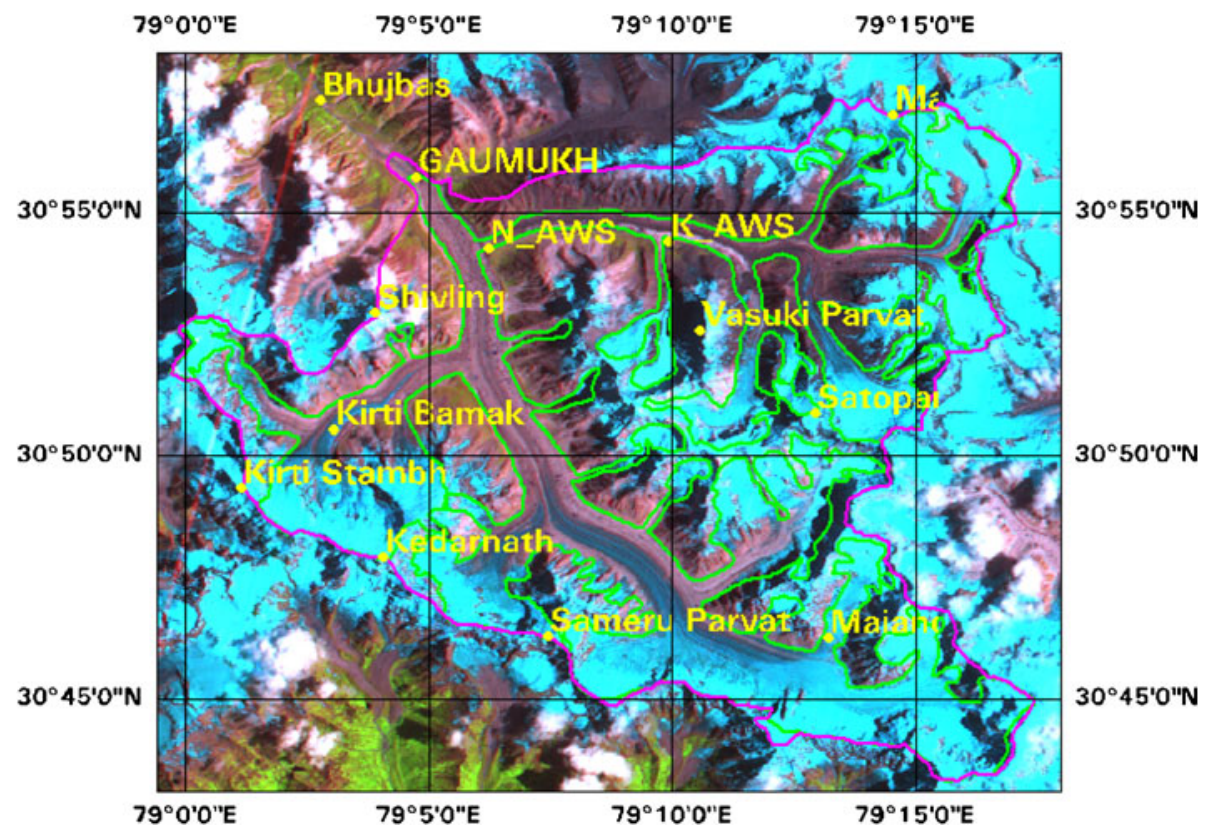

Figure 1. Study area shown by IRS-1C, LISS-III image of 9 August 2005; Pink polygon represents Gangotri sub-basin; Green polygon represents glacier boundary based on SoI mapsheet of 1962 and yellow points are settlements.

classes were arranged according to the coincidence of any two input classes. This output image was finally used for the interpretation of different classes and their class change. Further, three

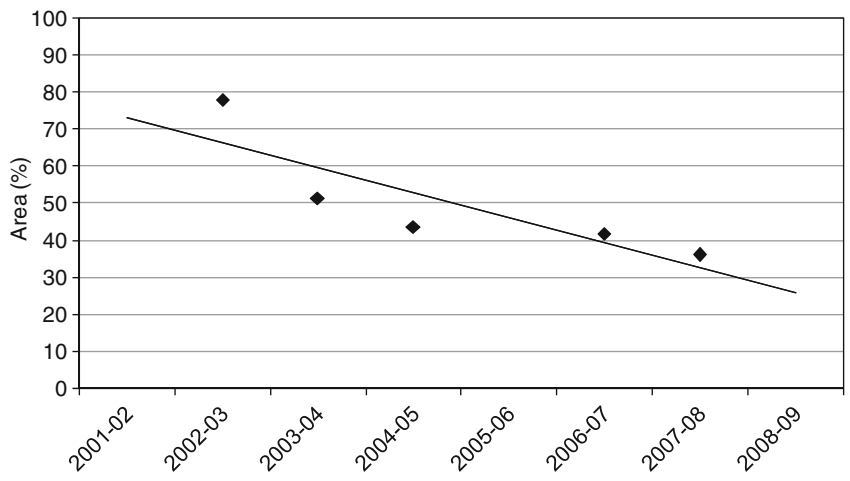

(a)

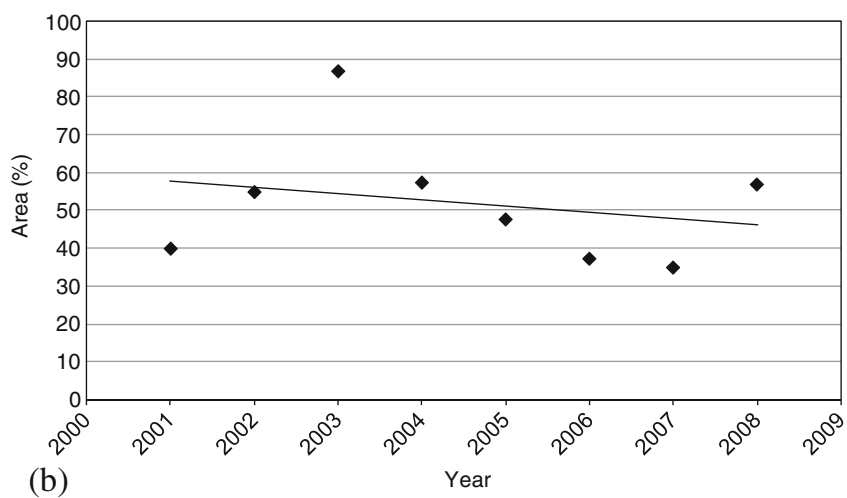

Figure 2. Estimated snow cover area using satellite data of (a) winter season (November-April) and (b) summer season (May-October). images were generated such as, no change, change to higher classes and change into lower classes. In this study, changes in to lower classes were considered, where snow/ice reflectance decreased due to melting or mixing. Such glacio-morphological
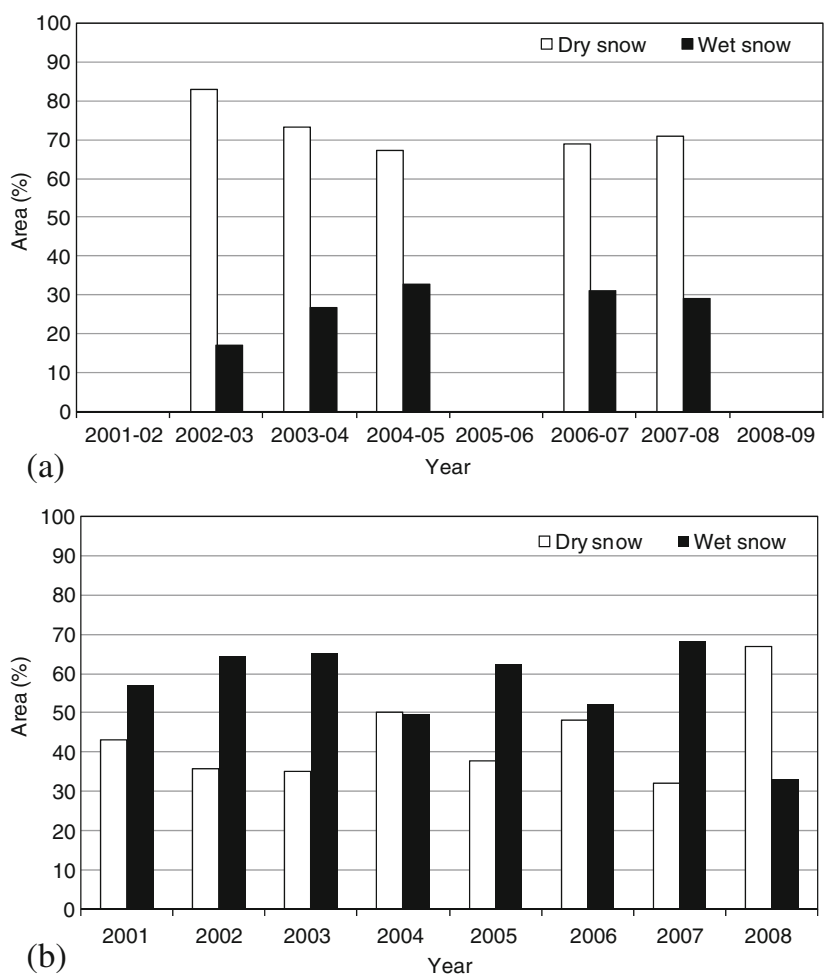

Figure 3. Comparison of estimated dry and wet snow cover area using satellite data of (a) winter season (NovemberApril) and (b) summer season (May-October). 

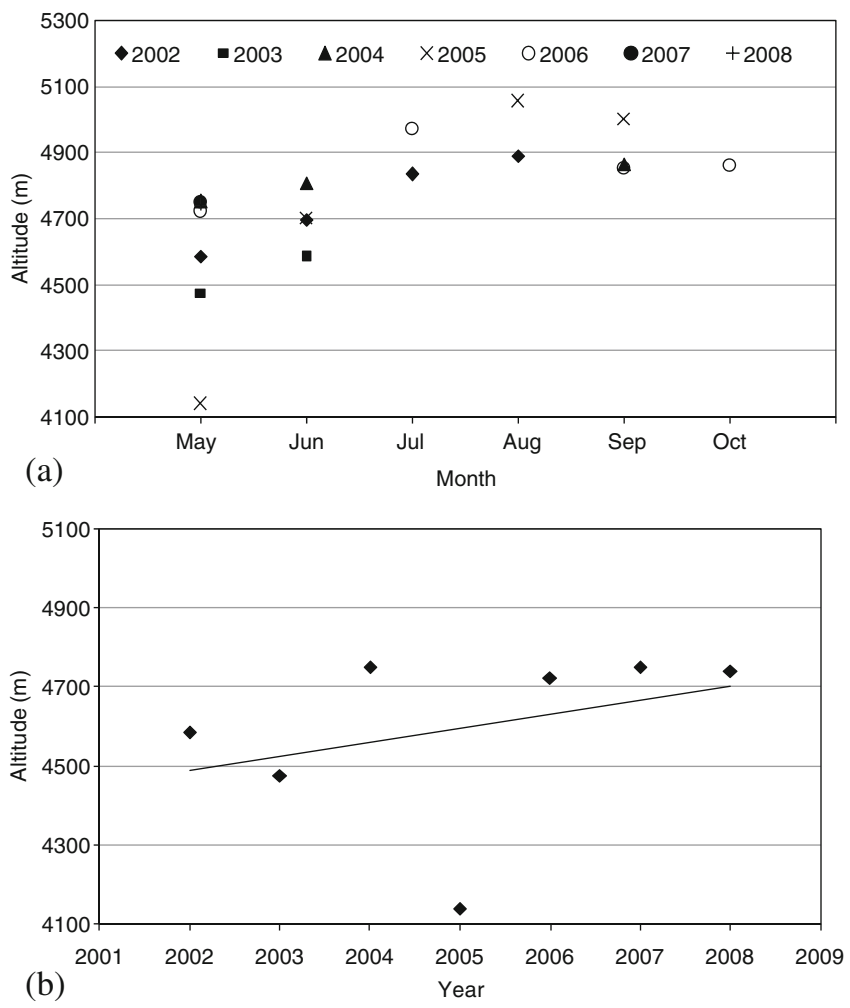

Figure 4. (a) Variation in wet snow line altitude and (b) altitude-wise changes in wet snow line in month of May.

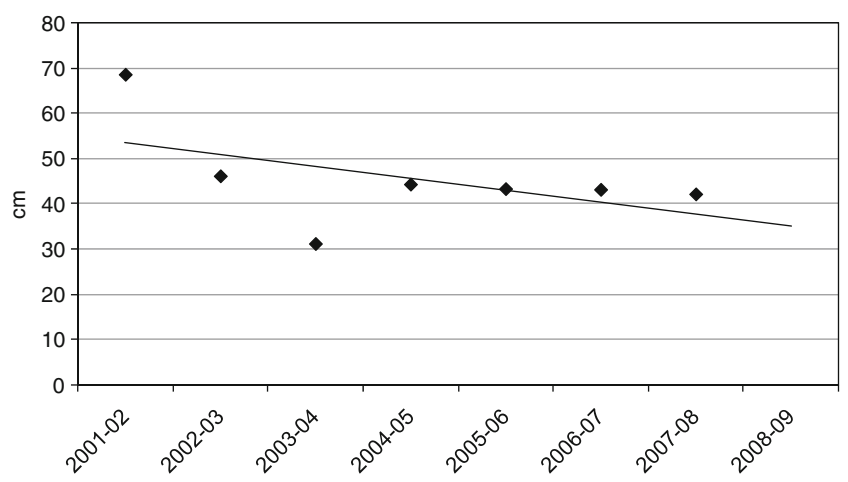

(a)

Year



Figure 5. (a) Average fresh snowfall amount of winter season (November-April) and (b) average rainfall amount of summer season (May-October) from ground observations data. changes were verified with high resolution satellite imagery as well as with field photographs during ground survey.

\section{Results and discussions}

The digital database of Gangotri glacier consisting different GIS layers such as glacier boundary, sub-basin boundary, and settlements generated using mapsheets and satellite imageries (PAN and LISS-III) are shown in figure 1. The snow covered area (SCA) estimated using LISS-III multitemporal satellite data for seven years between October 2001 and May 2008. Based on the season, 21 scenes of summer (May-October) and 12 scenes of winter (November-April) were analysed and average of summer period and winter period were carried out for each year. The less number of winter scenes is because most of the time the study area was found cloudy on the satellite date of pass and secondly the revisit time of the sensor was also poor (24/25 days). The seasonal snow cover area analysis shows an overall decreasing trend for winter (figure 2a). Similar decreasing trend of seasonal snow cover area was observed for summer with some points of higher snow cover area which
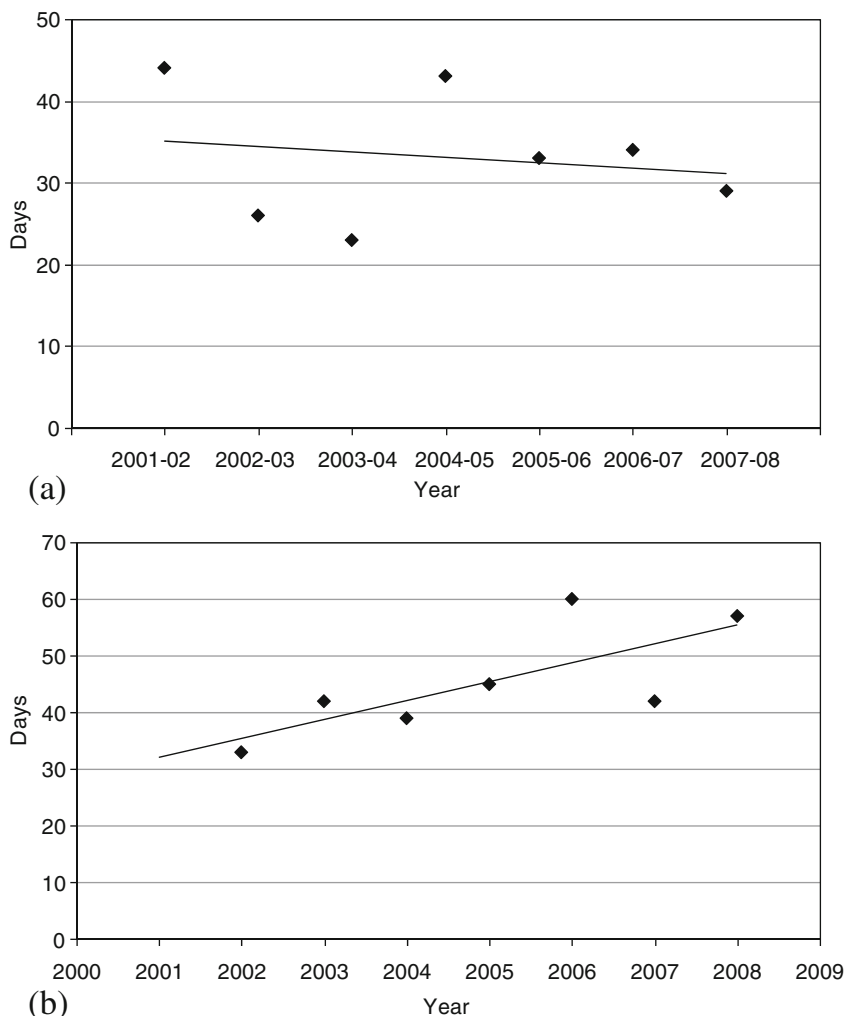

Figure 6. (a) Number of fresh snowfall days during winter season (where snowfall day is considered if any amount of fresh snowfall occurred in one day) and (b) number of rainy days during summer season (where rainy day is considered if any amount of rain occurred in one day). 


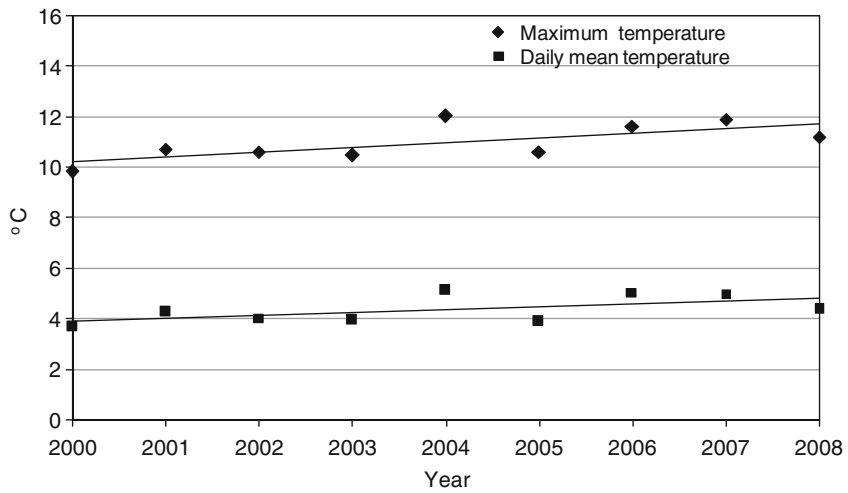

Figure 7. Maximum and daily mean temperatures pattern between year 2000 and 2008 .

may be due to snowfall in May or June (figure $2 \mathrm{~b})$. The estimated dry and wet snow cover area indicate that dry snow cover prevails during winter period (November-April) and snow remains dry for maximum area (figure 3a). However, during summer period (May-October), snow generally remains wet, except when area receives an unusual snowfall on higher reaches just before the satellite date of pass, i.e., years 2004 and 2008 (figure $3 \mathrm{~b})$. The variation in wet snow line with respect to

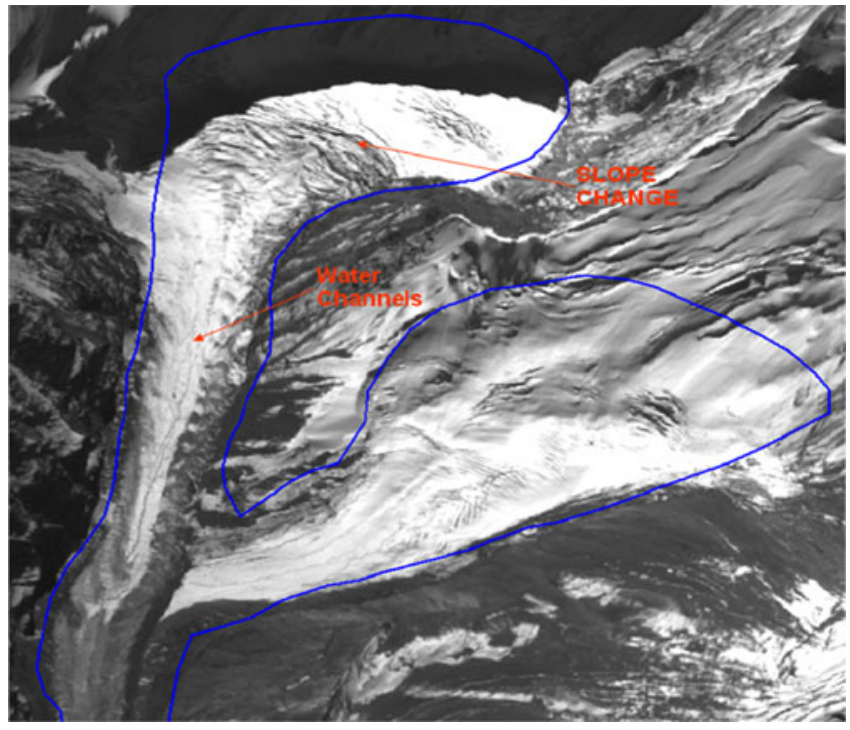

Figure 9. Glacio-morphological features observed by Cartosat-1 satellite data of 28 September 2006.

altitude shows an overall ascending trend for month-wise between May and August (figure 4a). Further September onwards, wet snow line altitude starts descending may be due to early snowfall at
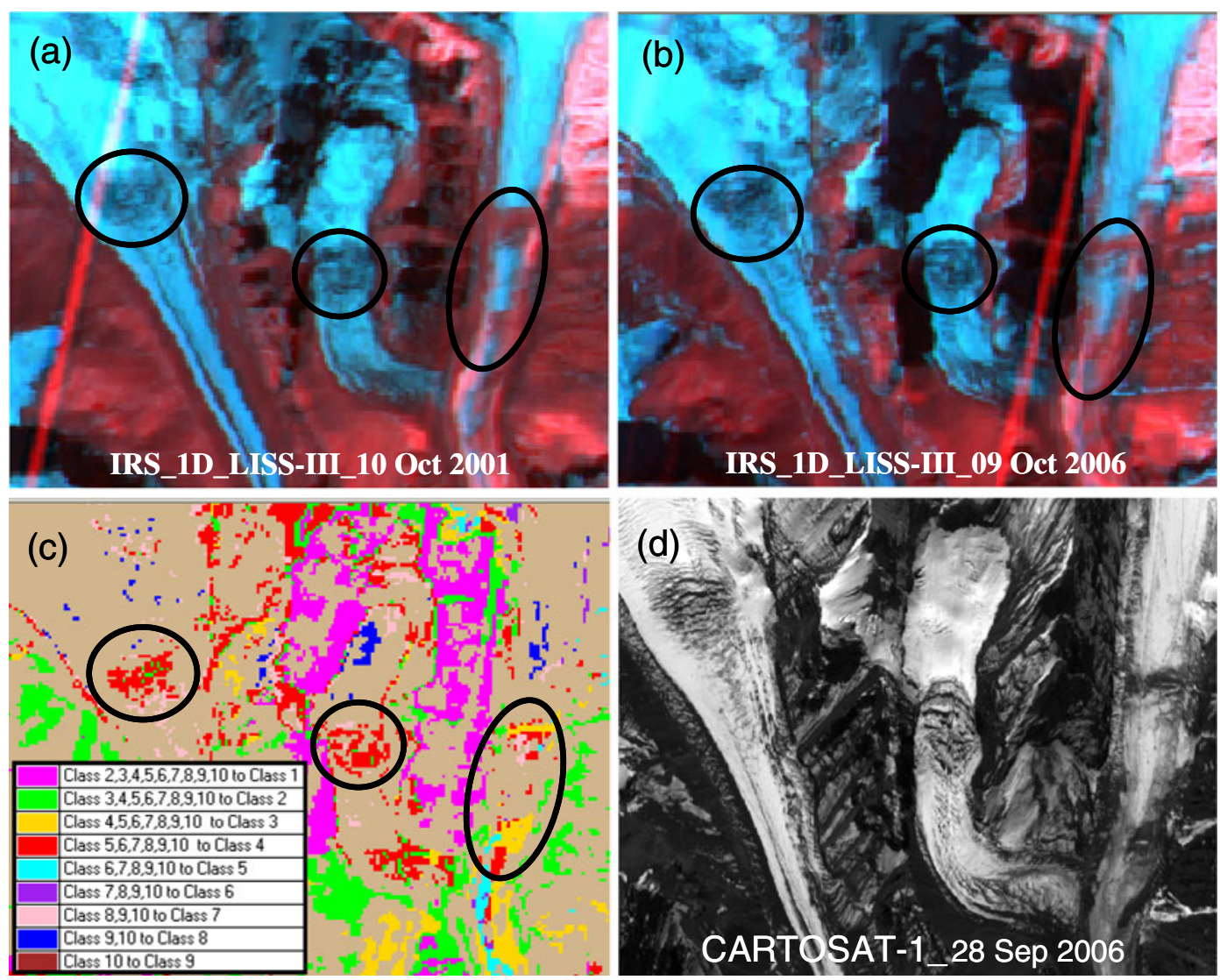

Figure 8. Changes in glacio-morphology constrained by topography. (a) LISS-III data of 10 October 2001; (b) LISS-III data of 9 October 2006; (c) change detection image with red colour indicating snow class present in earlier image changed into another class/decreased reflectance in later image; (d) Cartosat-1 image of 28 September 2006. 
high altitudes. An increasing trend of wet snow line altitude was observed in May, i.e., beginning of the summer season (figure 4b). Therefore large duration of wet snow on glacier surface and ascending trend of wet snow line are assumed to cause fast snow melting and initiate wet snow avalanches, which may further lead to the deposition of debris on glacier bed by scouring from adjoining slopes. In the present analysis the period of study is small (i.e., seven years) to know about the trend, however, this period provides the positive indication of reduction in snow cover area. Similar observations were also reported by Mohite et al. (2007) for a period of two years.

The precipitation data (fresh snowfall and rainfall) recorded between year 2001 and 2008 shows a decreasing trend of average fresh snowfall amount during winter (figure 5a) and an increasing trend for average rainfall amount during summer (figure 5b). This support the decreasing trend of SCA retrieved using satellite data. The increased average rainfall amount also suggests the increased wet snow cover condition. The study area
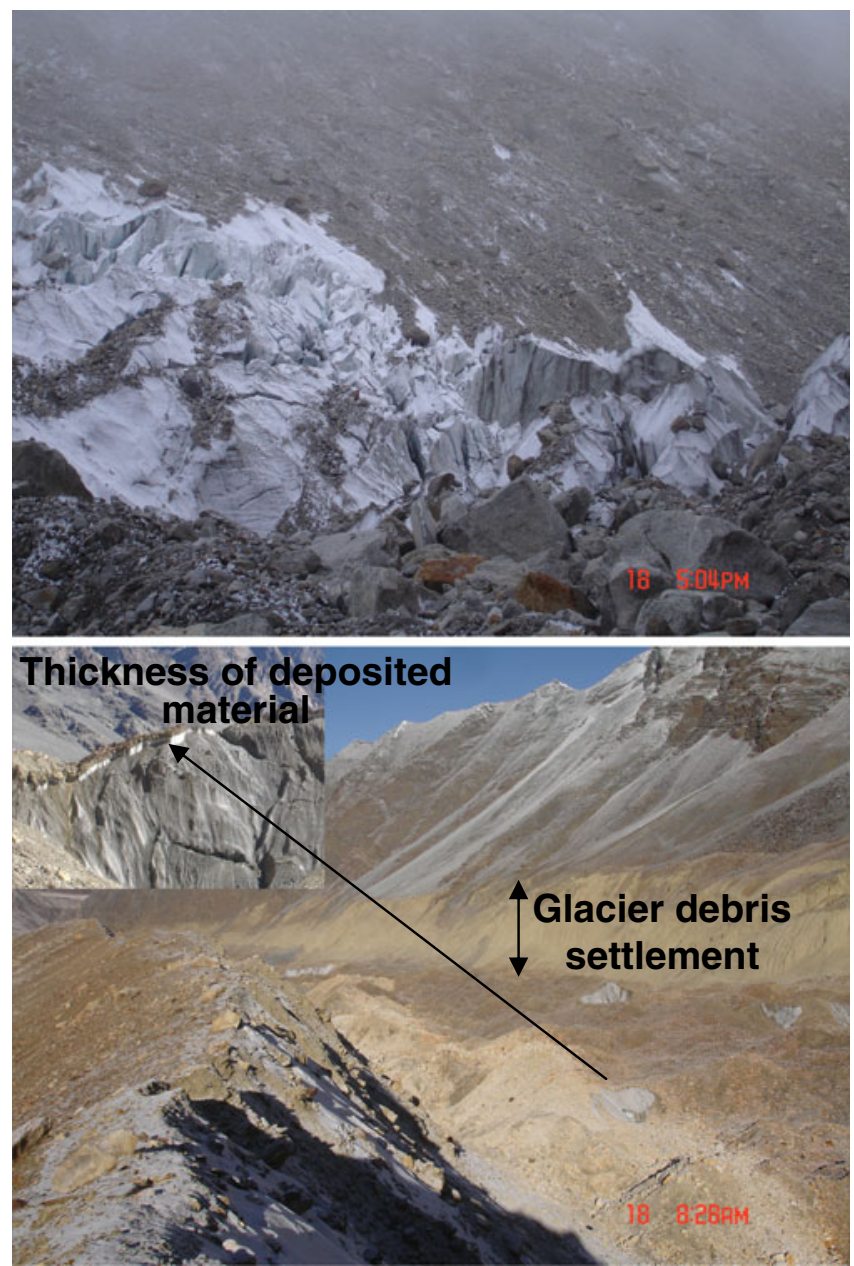

Figure 10. Field photographs of 18 October 2009 showing scouring of slopes and settlement of glacier debris. received snowfall every year between December and April, sporadic snowfall pattern between May and June, and no snowfall between July and August. However, rainfall was observed between May and September in each year and few rainfall days in April and October. Further decreasing trend in number of fresh snowfall days was observed during winter season (figure 6a) and increasing trend in number of rainy days was observed during summer (figure 6b). This shows the short period of winter snowfall and short spread of rainfall period in the Gangotri sub-basin. This also supports the analysis of satellite retrieved SCA and snow cover conditions. The temperature data recorded for nine years shows an overall rising trend in the daily mean and maximum temperatures observed between 2000 and 2008 (figure 7). This rising trend of daily mean and maximum temperature within study area also supports the snow cover conditions and causes of fast melting.

The geomorphology of Gangotri glacier shows that half of the glaciated region is having northern aspect, $30 \%$ is having southern, and remaining $10 \%$ having eastern and western aspects respectively. The majority of the active glacier bed lies on gradual slopes ranging between 0 and $15^{\circ}$, however there are many pockets having steeper topography with abrupt change in slope. These abrupt
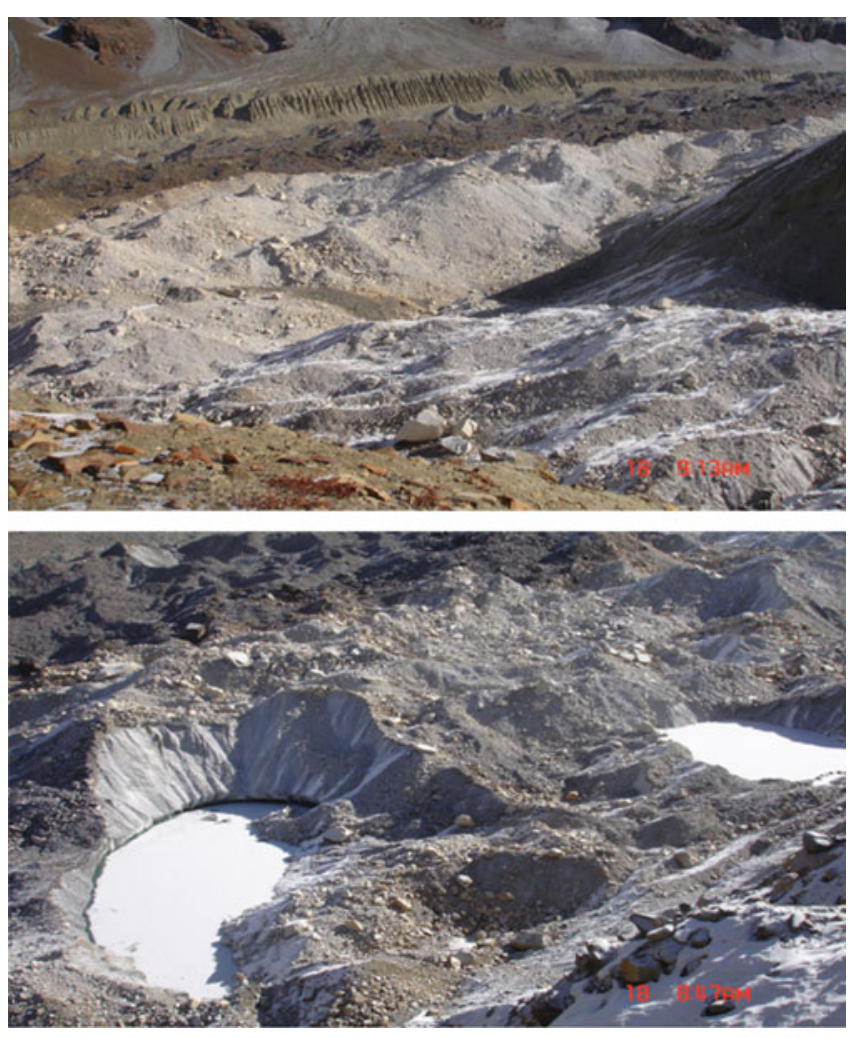

Figure 11. Field photographs of 18 October 2009 showing settlement of glacier debris and formation of number of glacial lakes. 
changes in slope within glacier bed have significant effect on the glacier health giving rise to a discontinuity or crevasses formation in the glacier bed. The change in glacier health is effectively confined to these abrupt slope changes, such as the walls of open crevasses and other holes on the glacier surface. Ablation proceeds by the preferential melting and retreat of such slopes is known as backwasting (Douglas and David 1998). The rate of backwasting depends on the area of exposed ice slopes, this can accelerate when holes on a glacier enlarge and increase in their perimeter (Douglas and David 1998). Mainly such changes were observed in the higher regions within glacier bed. These areas were identified using LISS-III images of 10 October 2001 and 9 October 2006 and significant changes were estimated as encircled areas in figure 8. Further, these changes were also verified with high resolution Cartosat-1 (IRS P5) imagery of 28 September 2006, where different surface water channels can be observed originating from discontinued areas (figure 9).

The field photographs of October 2009 exhibit the deposited material scoured from the adjoining slopes on the glacier bed. Such deposited material on glacier may increase the melting as well as settlement, as the thickness of this deposited material layer was observed small (less than $20 \mathrm{~cm}$ ). In case of thin debris layer, the effect of albedo is more to enhance the ablation, as debris covered snow/ice surface have a lower albedo than snow/ice, which absorb more short-wave radiation and heat up. Thereafter, it re-emits long wave radiation and adjacent ice experience more ablation than it would be in the absence of debris cover. Secondly, debris can also protect underlying snow/ice by shielding it from incoming radiation or atmospheric heat and thus reducing the ablation, but this occurs if the debris cover is thick enough to prevent heat from the surface being conducted through to the ice during the course of the daily temperature cycle (Douglas and David 1998). Thus the settlement can be observed from field photographs due to thin deposited material, which clearly discriminates the glacier debris with side walls (figures 10 and 11). In addition, the presence of supraglacial lakes and their increased number can be observed during field visit (figure 11b) and satellite imageries between 2001 and 2009 (figure 12), respectively.

A decrease of $6 \%$ in overall area of Gangotri glacier is observed between years 1962 and 2006, shows the deglaciation (figure 13). This decrease is observed maximum in the slope range between $0^{\circ}$ and $15^{\circ}$ and majority of the active glacier bed lies in this slope range. Overall deglaciation has also been observed by Kulkarni et al. (2011) in Bhagirathi basin for all 212 glaciers between 1962 and 2001. This variation in reduction of glaciated area mainly depends on the extent of the glacier (Kulkarni et al. 2011).

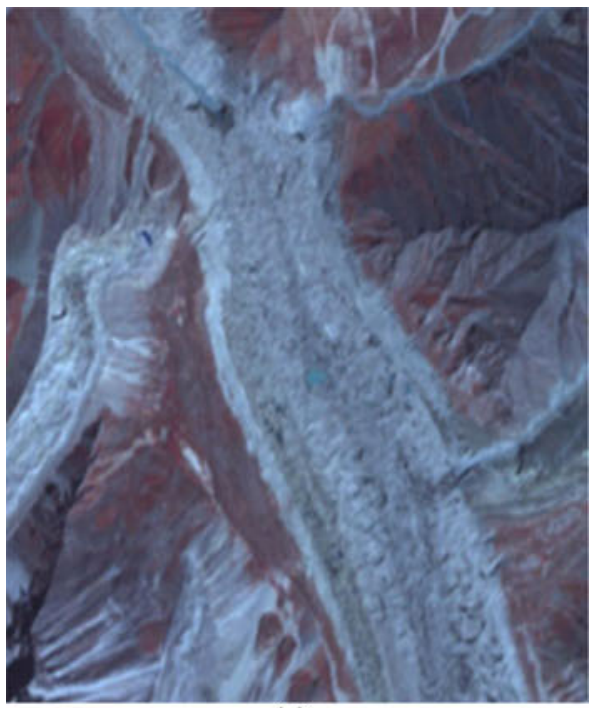

(a)



(b)

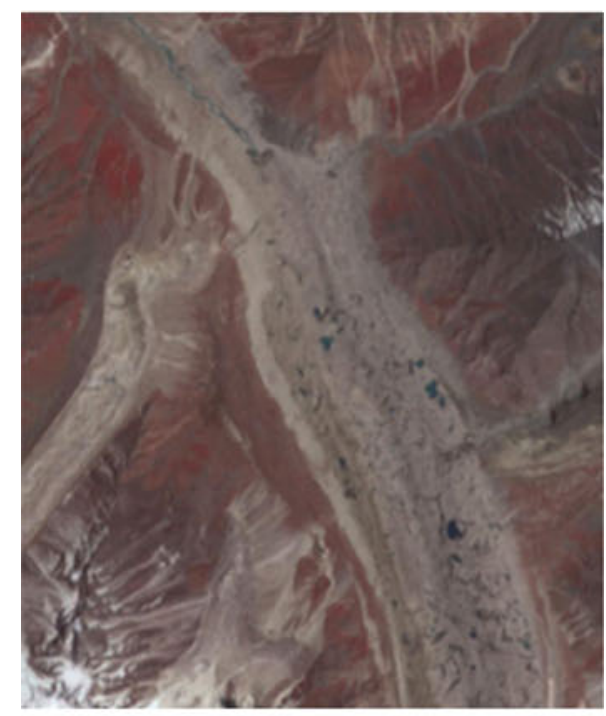

(c)

Figure 12. Formation of supraglacier lakes in Gangotri glacier observed by satellite data of (a) 9 September 2001, (b) 23 September 2006, and (c) 20 June 2009. 


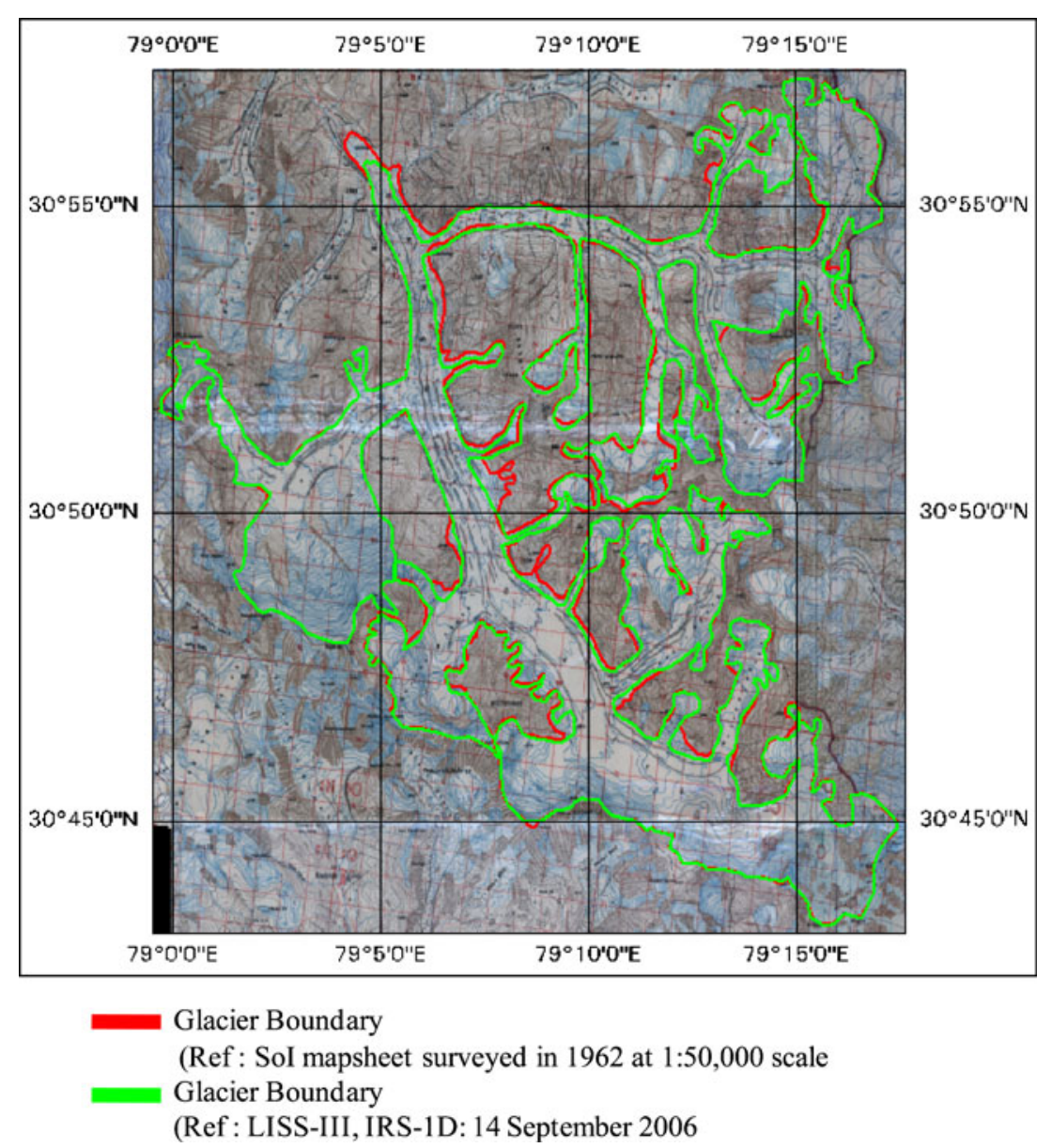

Figure 13. A loss in overall area of Gangotri glacier from 1962 to 2006.

\section{Conclusions}

The potential of the satellite remote sensing was explored for monitoring the Gangotri glacier for a period of seven years. The observed changes in snow cover area and snow characteristics were validated using field collected snow-meteorological data and field visit. Further, the analysis of continuous observed snow-meteorological data of the region also supports the previous studies carried out by different researchers, which show the retreat of Gangotri glacier. The combinations of prevailing wet snow period, increasing trend of average temperatures, rainfall amount and rainy days lead to fast melting, scouring of adjoining slopes and shrinking of glacier bed. A number of glacial lakes have been observed during field survey, which also indicates the rise in temperature. In addition, terrain analysis suggests that abrupt slope change in glacier bed is also an important factor affecting the glacier health. This study has shown that the changes on glacier surface are due to climatic and topographic (local geomorphology) factors, which decreased overall glaciated area by $6 \%$ between 1962 and 2006. This study is also helpful in understanding the different fluctuation records of Himalayan glaciers lying in the same climatic zone and increase in the number of glaciers due to fragmentation.

The authors feel that the recently launched LISS-III sensor onboard on Resourcesat-2 satellite, with good radiometric resolution can avoid the sensor saturation limitation of earlier LISS-III sensors. To overcome the persistent cloudy conditions over the area, potential of Synthetic Aperture Radar (SAR) such as RISAT (IRS) can be very useful in monitoring wet snow and other glacier parameters. Other techniques such as lidar survey and cryostat2 satellite data can be explored for glacier health and mass balance related studies.

\section{Acknowledgements}

The authors are thankful to all SASE's persons who helped in collecting the snow-meteorological data. We also thank Kamlesh Sharma and Rajeev Kumar of SASE for collecting the field photographs and DEAL (DRDO), Dehradun for providing LISSIII data. 


\section{References}

Bahuguna I M 2003 Satellite stereo data analysis in snow and glaciated region. Training document: Course on remote sensing for glaciological studies; Manali, India, SAC/RESA/MWRG/ESHD/TR/13/2003, pp. 85-99.

Bahuguna I M, Kulkarni A V, Nayak S, Rathore B P, Negi H S and Mathur P 2007 Himalayan glacier retreat using IRS 1C PAN stereo data; Int. J. Remote Sens. 28(2) 437-432.

Bhutiyani M R 1999 Mass-balance studies on Siachen Glacier in the Nubra valley, Karakoram, Himalaya, India; J. Glaciol. 45(149) 112-118.

Bhutiyani M R, Kale V S and Pawar N J 2007 Long-term trends in maximum, minimum and mean annual air temperatures across the northwestern Himalayan during the 20th century; Climate Change 85 159-177.

Bhutiyani M R, Kale V S and Pawar N J 2008 Changing stream flow patterns in the rivers of northwestern Himalaya: Implications of global warming in the 20th century; Curr. Sci. 95(5) 618-626.

Chavez P S Jr 1988 An improved dark-object subtraction technique for atmospheric scattering correction of multispectral data; Remote Sens. Environ. 24 459-479.

Colbeck S C 1982 An overview of seasonal snow metamorphism; Rev. Geophys. Space Phys. 20(1) 45-61.

Dobhal D P, Gergan J T and Thayyen R J 2004 Recession and morphogeometrical changes of Dokriani glacier (1962-1995) Garhwal Himalaya, India; Curr. Sci. 86(5) 692-696.

Douglas I B and David J A E 1998 Glaciers $\&$ Glaciations; 1st edn., Arnold Publishers, London.

Dozier J 1989a Remote sensing of snow in the visible and near-infrared wavelengths; In: Theory and Applications of Optical Remote Sensing (ed.) Asrar G (New York: John Wiley and Sons), pp. 527-547.

Dozier J 1989b Spectral signature of alpine snow cover from the Landsat Thematic Mapper; Rem. Sens. Environ. 28 9-22.

Gupta R P, Haritashya U K and Singh P 2005 Mapping dry/wet snow cover in the Indian Himalayas using IRS multispectral imagery; Rem. Sens. Environ. 97(4) 458-469.

Hall D K, Riggs G A and Salomonson V V 1995 Development of methods for mapping global snow cover using moderate resolution image spectroradiometer data; Rem. Sens. Environ. 54(2) 127-140.

Hansen J and Nazarenko L 2004 Soot climate forcing via snow and ice albedo; PNAS 101(2) 423-428.

Hasnain S I 2008 Impact of climate change on Himalayan glaciers and glacier lakes; Proc. Taal 200\%, The 12th Lake conference, pp. 1088-1091.

IPCC 2007 Summary for Policymakers, In: Climate Change 2007 The Physical Science Basis. Contribution of Working Group I to the Fourth Assessment Report of the Intergovernmental Panel on Climate Change (eds) Solomon S, Qin D, Manning M, Chen Z, Marquis M, Averyt K B, Tignor M and Miller H L (Cambridge, UK and New York, USA: Cambridge University Press).

Krishna A P 1996 Satellite remote sensing applications for snow cover characterization in the morphogenetic regions of upper Tista River basin, Sikkim Himalaya; Int. J. Remote Sens. 17(4) 651-656.

Konig M, Winther J G and Isaksson E 2001 Measuring snow and glacier properties from satellite; Rev. Geophys. 39 $1-27$.

Kulkarni A V 1992a Mass balance of Himalayan glaciers using AAR and ELA methods; J. Glaciol. 38(128) 101-104.
Kulkarni A V 1992b Glacier inventory in the Himalaya. Natural resources management - a new perspective; NNRMS, Bangalore, pp. 474-478.

Kulkarni A V 2007 Effect of global warming on the Himalayan cryosphere; Jalvigyan Sameeksha 22 93-108.

Kulkarni A V and Bahuguna I M 2002 Correspondence. Glacial retreat in the Baspa Basin, Himalayas, monitored with satellite stereo data; J. Glaciol. 48(160) 171-172.

Kulkarni A V, Mathur P, Rathore B P, Suja Alex, Thakur N K and Kumar M 2002a Effect of global warming on snow ablation pattern in the Himalayas; Curr. Sci. 83(2) 120-123.

Kulkarni A V, Srinivasulu J, Manjul S S and Mathur P 2002b Field based spectral reflectance to develop NDSI method for snow cover monitoring; J. Indian Soc. Rem. Sens. 30(1-2) 73-80.

Kulkarni A V, Mathur P, Singh S K, Rathore B P and Thakur N K 2004 Remote sensing based techniques for snow cover monitoring for the Himalayan region; International symposium on snow monitoring and avalanches (ISSMA-04), Manali, India, pp. 399-405.

Kulkarni A V, Rathore B P, Mahajan S and Mathur P 2005 Alarming retreat of Parbati glacier, Beas basin, Himachal Pradesh; Curr. Sci. 88(11) 1844-1850.

Kulkarni A V, Philip G, Thakur V C, Sood R K, Randhawa S S and Chandra R 2007 Glacier inventory of the Satluj Basin using remote sensing technique; Him. Geol. 20(2) $45-52$.

Kulkarni A V, Rathore B P, Singh S K and Bahuguna I M 2011 Understanding changes in the Himalayan cryosphere using remote sensing techniques; Int. J. Remote Sens. 32(3) 601-615.

Kumar K, Dumka R K, Miral M S, Satyal G S and Pant M 2008 Estimation of retreat rate of Gangotri glacier using rapid static and kinematic GPS survey; Curr. Sci. 94(2) $258-262$.

Markham B L and Barker J L 1986 Landsat MSS and TM post-calibration dynamic ranges, exoatmospheric reflectances and at-satellite temperature; EOSAT Technical Notes 1 3-8.

Mohite K, Singh G and Venkataraman G 2007 Feasibility of various remote sensing data for mapping snow cover area around Gangotri glacier; Proc. SPIE 6787 67872E; doi: $10.1117 / 12.753441$.

Nainwal H C, Negi B D S, Chaudhary M, Sajwan K S and Gaurav A 2008 Temporal changes in rate of recession: Evidences from Satopanth and Bhagirath Kharak glaciers, Uttarakhand, using Total Station Survey; Curr. Sci. 94(5) 653-660.

Naithani A K, Nainwal H C, Sati K K and Prasad C 2001 Geomorphological evidences of retreat of the Gangotri glacier; Curr. Sci. 80(1) 87-88.

Negi H S, Kulkarni A V and Semwal B S 2009 Study of contaminated and mixed objects snow reflectance in Indian Himalaya using spectroradiometer; Int. J. Remote Sens. 30(2) 315-325.

Negi H S, Singh S K, Kulkarni A V and Semwal B S 2010 Field-based spectral reflectance measurements of seasonal snow cover in the Indian Himalaya; Int. J. Remote Sens. 31(9) 2393-2417.

Negi H S and Kokhanovsky A 2011 Retrieval of snow albedo and grain size using reflectance measurements in Himalayan basin; The Cryosphere 5 203-217.

O'Brien H and Munis R H 1975 Red and near-infrared spectral reflectance of snow; Research Report, 332 Hanover, NH' U.S. Army CRREL.

Paterson W S B 1994 The Physics of Glaciers, 3rd edn, Pergamon Press. 
Philip G and Ravindran K V 1998 Glacial mapping using Landsat thematic mapper data: A case study in parts of Gangotri glacier, NW Himalaya; J. Indian Soc. Remote Sens. 26(1-2) 29-34.

Racoviteanu A E, Williams M W and Barry R G 2008 Optical remote sensing of glacier characteristics: A review with focus on the Himalaya; Sensors 8 3355-3383; doi: $10.3390 / \mathrm{s} 8053355$.

Salomonson V V and Appel I 2004 Estimating fractional snow cover from MODIS using the normalized difference snow index; Rem. Sens. Environ. 89 351-360.

Singh V P, Singh P and Haritashya U K 2011 Encyclopedia of snow, ice and glaciers; Springer, Dordrecht, The Netherlands.

Song C, Woodcock C E, Seto K C, Lenney M P and Macomber A S 2001 Classification and change detection using Landsat TM data: When and how to correct atmospheric effects; Remote Sens. Environ. 75 230-244.

Srinivasulu J 2003 Snow reflectance estimation using remote sensing techniques. Training document: Course on remote sensing for glaciological studies; Manali, India, SAC/RESA/MWRG/ESHD/TR/13/2003, pp. 25-32.

Srinivasulu J and Kulkarni A V 2004 A satellite based spectral reflectance model for snow and glacier studies in the Himalayan terrain; Proc. Indian Acad. Sci. (Earth Planet. Sci.) 113 117-128.

Venkataraman G, Rao Y S and Rao K S 2005 Application of SAR interferometry for Himalayan glaciers, Proc. of Fringe Workshop: 28 November-2 December, Frascati, Italy, 28.1-28.6.

Yasunari T J, Bonasoni P, Laj P, Fujita K, Vuillermoz E, Marinoni A, Cristofanelli P, Duchi R, Tartari G and Lau K M 2010 Estimated impact of black carbon deposition during pre-monsoon season from Nepal Climate Observatory - Pyramid data and snow albedo changes over Himalayan glaciers; Atmos. Chem. Phys. 106603 6615.

Wiscombe W J and Warren S G 1980 A model for the spectral albedo of snow-I: Pure snow; J. Atmos. Sci. 37 2712-2733. 